\title{
Community Interpreter Training in the United States and the United Kingdom: An Overview of Selected Initiatives
}

\begin{abstract}
Community interpreter training opportunities are growing all over the world. A heightened awareness of the need for competent interpreters in legal settings has carried over into other areas, resulting in a positive impact on community interpretation in general. Consequently, many non-profit organizations, professional associations, academic institutions, and government agencies are becoming involved in upgrading the competence and professionalizing the image of the community interpreter. Concentrating on the United States and the United Kingdom, the current article discusses a number of promising developments in this field.
\end{abstract}

\section{Introduction}

During the past ten years, much attention has been focused on court interpretation and court interpreter training around the world (AUSIT 1992; Burley 1990; Chapman 1990; de Jongh 1990; Flynn 1985; Khoon 1990; Moerman 1991; Morris 1990; Roberts and Tayler 1990; Schweda Nicholson 1992, 1991, 1990a, 1989, 1987, 1986a, 1986b; and Sheppard 1992). With increasing frequency, the progress achieved in the courts is having a positive impact on the provision of interpretation services in other areas, which include medical and mental health consultations, financial and employment matters, immigration hearings, and law enforcement as well as a variety of social assistance programs like housing aid, disaster relief, and family counseling (to name only a few) where trained, professional interpreters are desperately needed (Downing and Tillery 1992; Molyneux-Berry 1992; O’Brien 1985; Per-Lee, Cogswell and Pace 1985; Sanders 1992; Schweda Nicholson, In Press, Forthcoming, 1990b; and Wilder 1985).

* Nancy Schweda Nicholson

Department of Linguistics

46 E. Delaware Avenue

University of Delaware

Newark, Delaware 19716-2551

USA 
As more and more people recognize the requirement for competent, professional interpreters in these settings as well, community interpreter training and certification programs are developing rapidly. However, a prevailing problem in multilingual/multicultural societies is the need for training in as many as 30 or more languages, with perhaps only one or two speakers of a particular language. It is often impractical and financially quite impossible to offer a full-blown course for only a handful of people in a specific language combination, especially when so few trainers exist and are available to offer specialized programs of instruction.

In light of the above, the current paper examines several approaches to community interpreter training in the United States and the United Kingdom, whose societies are characterized by a broad ethnic and linguistic diversity. The discussion highlights the problems and challenges involved in community interpreter education.

\section{The "Community Interpreter" Defined}

What is a "community interpreter"? Sanders (1992:45) defines this individual as ". . .someone who facilitates access to public services for people whose first or preferred language is not that of the host country. . . [A]ccess to such services is more often than not hampered by a communication barrier that goes beyond language. This barrier is a many-faceted one that includes culture, class, race, often gender and, above all, status". As such, factors to be considered in any community interpreting situation include: (1) the many possibilities for misunderstandings and even lack of communication due to cultural and linguistic differences; (2) the potential for racial prejudice; and (3) the difference between the status and power of the service provider and the relative powerlessness of the client, in many cases. Sanders continues: "The community interpreter interprets between two, or more, people who are not equal and so her role is invariably to bridge a power gap as well as a language and culture gap" (1992:45). (For an additional definition of "community interpreter", see Shackman 1984).

It is clear from the above definition that the community interpreter's function is oftentimes far more complicated and diverse than that of the traditional conference interpreter. While many of the basic characteristics remain the same (such as the requirements for: (a) competence in both source and target languages; (b) an excellent knowledge of interpreting skills; (c) a complete and accurate rendering of the source language message in the target language; and (d) a broad understanding of the inter- 
play between source and target cultures), it can be convincingly argued that the community interpreter is constantly faced with both linguistic and extralinguistic challenges which generally do not present themselves in a typical conference situation (See, for example, Mindess 1992 for a discussion of cross-cultural sensitivity).

\section{Approaches to Community Interpreter Training}

\subsection{The United States}

Great progress has been achieved in the United States during the past decade. As mentioned in the introduction, the attention paid to court interpretation services, boosted tremendously by passage of the Court Interpreters Act of 1978 (Public Law 95-539), has recently translated to an enthusiastic interest in providing quality community interpretation services in a variety of medical and social services settings. Moreover, several government agencies have become involved in in-house interpreter training.

\subsubsection{Interpreter Training in Community Organizations and Academic Institutions}

The Twin Cities Interpreter Project (TCIP), a group of professionals in the Minneapolis-St. Paul (Minnesota) area concerned with the provision of quality interpreting services in various community settings, was created in 1989 (Downing and Tillery 1992). It became specifically involved in offering a series of courses for Southeast Asian refugee mental health interpreters during 1991. As a primary instructor during an intensive consecutive course, the author worked with speakers of Hmong, Cambodian (Khmer), Vietnamese, and Lao. Each trainee also had English as a working language. The goal of the program was to make trained interpreters available for mental health interviews and evaluations. The Southeast Asian community evidenced a particular need for interpreters in this setting, as many of its members had been exposed to unspeakable horrors in their home countries and, as a result, suffered from various types of mental illness. Language enhancement, terminology building, and medical procedures were fundamental components of the class in addition to the skills of consecutive interpretation. The course was deemed a success by all involved. (For a detailed report on the TCIP and its training program, see Schweda Nicholson: In Press). 
In Honolulu, Hawaii, the Bilingual Access Line (BAL), an arm of Helping Hands, Hawaii (a United Way Agency), has provided interpreters for numerous languages in many different situations since its creation in 1985. Usage statistics indicate that, on an annual basis, interpreter services are requested for well over 50 languages in the areas of medical care, mental health, the law, education, finance, child and/or spouse abuse, housing, employment, and visitor assistance, to name only a few.

The BAL has developed a 30-minute videotape entitled "Providing Services with an Interpreter" and an accompanying brochure. Each new interpreter must view this tape as part of an orientation procedure. Regarding language ability, the majority of the BAL employees are native speakers of languages other than English. In the past, no formal evaluation of the other languages was conducted because it was assumed that, since the individuals are native speakers, they have a good to excellent command of those languages. However, a new screening procedure has been developed recently. Prospective interpreters participate in a roleplaying exercise in which the BAL Director, Stuart Robson (a native speaker of English) plays the part of a physician, and another BAL employee (an expert in the candidate's native language) acts as the patient. In this way, both English and native language skills are assessed. According to Robson, the role-playing scenario serves two purposes: (1) it screens out those who are not qualified and (2) it acts as an initial training exercise for those applicants who are chosen. Since implementation of the new screening procedure, more than one-half of the prospective interpreters have been rejected (Robson 1993).

Shortly after its establishment in 1985, some specialized training was provided to BAL interpreters. Representatives from the police department, a hospital, and a victim witness program came to talk about the role of the interpreter and ethical considerations. Since much of the BAL's work was crime-related at the beginning, additional training sessions were held with the prosecutor's office and the Honolulu Police Department. In 1986, a grant was received so that the State Department of Health could train interpreters for mental health situations. With one or two interpreters per language in a larger class (all of whom had English as one of their working languages), mental health interpreter training was instituted. Some of the topics covered included: (1) mental health problems of immigrants and refugees; (2) the history of American psychiatry; (3) the diagnostic psychiatric interview; (4) transcultural psychiatry; (5) strategies for working with psychiatrists; and (6) the interpreter's responsibility: liability and confidentiality. Approximately six 2- 
hour sessions were held. Moreover, the BAL has also been involved in interpreter training for (1) medical situations which do not involve mental health; and (2) legal matters (Robson 1988).

As the Director of the newly-established Center for Interpretation and Translation (CIT) at the University of Hawaii at Manoa from 1987 to 1989, the author stressed community outreach. As a result, during her tenure at the University, she worked with community interpreters in the area of interpreting techniques and skills, with an emphasis on consecutive note-taking and note-reading. These seminars and workshops were extremely well-attended and the feedback was entirely positive.

Moreover, there was a strong interest in simultaneous training. In this connection, the author offered individualized training for the Assistant Director of the BAL, who is a native speaker of Lao. The session covered some basic pre-simultaneous exercises such as shadowing of fluent texts and shadowing of Hendrickx-type lag exercises. All of the work was done in English. This approach can be applied to any language combination, as long as the instructor and trainee share at least one working language. To be more specific, after an initial training period, the individual can practice on his or her own and work to perfect the skills. Further feedback from the instructor is offered during a subsequent session and, if all goes well, the trainee is then able to work with other groups who speak additional languages. Moreover, the student can also continue to practice with the lag exercises, but switch the emphasis from shadowing to interpretation from and into English. As a result of this particular trainee's abilities in Lao (skills not possessed by the author), he can become a trainer at an introductory level within his specific language combination. It is clear that, at least during the elementary stages, the shortage of trainers can be addressed in this manner. The "training of trainers" strategy of individual sessions which, in turn, grow to include other groups is viewed as a way of developing a basic cadre of trainers in lesser-used languages. Once the individual learns some of the very most basic techniques, he or she can pass along the skills to others. During subsequent sessions with the primary trainer, more difficult material can be tackled.

The BAL is also making an important contribution to the education of service providers. Robson offers training on working effectively with an interpreter to approximately four agencies per year. Included among the most recent organizations to benefit from this program are the Hawaii Family Stress Center and the Kalihi-Palama Health Center (Robson 1993). 
The University of Delaware Interpretation Program launched a series of summer seminars in 1992. During June of that year, a one-week intensive course in the basic skills of simultaneous and consecutive interpretation was offered on the Delaware campus. The working languages were English and Spanish. In August of 1993, a two-day seminar stressing consecutive interpretation skills was held. Once again, the working languages were English and Spanish. ${ }^{1}$ Participants in both courses came from varied backgrounds. Some were experienced interpreters who had been working without the benefit of training; others had never interpreted and wished to learn more about the field. Those trainees who were experienced had been involved in a wide variety of court and community interpretation settings. Evaluations were uniformly positive, and most of the students wrote that they wished the course had lasted longer. Two seminars are currently planned for the summer of 1994: one will emphasize the basic skills of simultaneous interpretation, and the other will be a "training of trainers" class.

At the recent American Translators Association (ATA) Annual Conference in Philadelphia (October 1993), the author was consulted regarding the establishment of a new community interpreter training program in Seattle, Washington. Based on the preliminary information provided to the author with respect to the organizers' philosophical approach, the screening and selection requirements, and the projected curriculum design, it promises to be a welcome addition to the growing number of such programs in the United States and around the world after various funding and administrative details are worked out.

\subsubsection{Interpreter Training in Government Agencies}

The Executive Office for Immigration Review (EOIR) is a branch of the United States Department of Justice. The EOIR, which most people believe to be an arm of the Immigration and Naturalization Service (INS), is an independent agency within the Department of Justice. The primary responsibility of the EOIR is to conduct exclusion and deportation hearings and apply relevant immigration laws. The author has acted as a consultant to and a trainer for the EOIR since 1989. Inasmuch as many of the respondents (those individuals whose cases come before EOIR judges) have traditionally been Spanish-speaking, the EOIR employs Lan-

1 Although the need for interpreters of a variety of Asian languages is growing in the United States, Spanish still remains (and will probably continue to remain) the language for which interpretation services are most needed in this country. 
guage Clerks, Language Assistants, and Language Specialists who, in addition to performing numerous administrative and clerical duties, often function as interpreters. Since the majority of the "Language Series" employees have been required to interpret without the benefit of proper training, the EOIR decided to launch a series of consecutive interpretation seminars in 1989. Large cities like New York and Chicago were selected as the training sites. The seminars met with an enthusiastic reception among EOIR employees, as the intensive classes (most of which were of two or three days' duration) provided them with the basic skills of consecutive interpretation, including note-taking and note-reading, short-term memory strengthening, public speaking skills, and preparation strategies. As of this writing, the EOIR is in the process of developing a series of interpretation performance standards by which current and prospective Language Series employees will be rated (Schweda Nicholson 1993).

The Federal Bureau of Investigation (FBI), also a branch of the U.S. Department of Justice, first became involved in interpreter training in 1990. In an association similar to that with the EOIR, the author has been both a consultant and a trainer for this federal agency. Inasmuch as many FBI Language Specialists are often required to interpret for Special Agents in a variety of law enforcement situations which include (but are not limited to) interviews/interrogations, polygraph examinations, and hostage negotiations, it was decided that training in the skills of consecutive interpretation should be provided on an intensive basis. The author served as the primary instructor for one-week courses offered at the FBI Academy in Quantico, Virginia, during the summers of 1990 and 1991. The consecutive interpretation training component was supplemented with lectures given by FBI personnel who are specialists in the areas described above. As with the EOIR employees, the seminars were very wellreceived. Various role-playing activities were included and students were instructed to write scenarios which closely resembled their day-to-day work. As a result, the trainees quickly identified the relevance and usefulness of the interpretation seminars to their job requirements and performance.

\subsection{The United Kingdom}

A 1989 survey by the Inner London Education Authority "revealed that 25 per cent of schoolchildren spoke a language other than English; 184 different European, Asian and African tongues were involved" (Sheppard 
1992:33). Moreover, almost one-third (50,000 out of 168,400) of Birmingham nursery and secondary school students (polled in a survey similar to that of the Authority) indicated that they speak a language other than English (Sheppard 1992). These statistics translate to not only a continuing but a growing need for those who can bridge the linguistic and cultural gaps which, according to the above data, are widespread in the United Kingdom.

It is encouraging to note that community interpreting in the British Isles has developed significantly during the past fifteen years, as evidenced by the interpreter training programs cited in Sanders (1992) and Shackman (1984). By way of introduction, primarily two levels of certification are available in the United Kingdom with respect to language and interpretation skills: (1) the Bilingual Skills Certificate (BSC); and (2) the Certificate in Community Interpretation (CCI). Obtaining the BSC can be viewed as an initial or preliminary step toward the CCI. The BSC examination "tests competence in English and another community language at an 'A-level' standard" (Toso 1988:19). Training courses which prepare candidates to take the BSC test are available at a number of institutions throughout Great Britain. It is important to stress that passage of the BSC examination does not inherently qualify the individual as a community interpreter. The BSC recognizes language skills, not interpretation skills. If the successful candidate wishes to continue by obtaining interpreter training, he or she can register for classes which prepare one for the CCI examination (Toso 1988).

In the early 1980s, the Institute of Linguists succeeded in securing funding from the Nuffield Foundation, a British charitable organization, in order to launch the Community Interpreting Project. The Project's courses are generally offered through an adult continuing education format and feature three basic specializations: (1) legal; (2) local government; and (3) medical services (Sanders 1992). An experimental interpreter training program was first offered in Peterborough. The course was limited in scope in that its goal was to prepare community interpreters to work specifically in the field of law enforcement. It was decided early on that a "language enhancement course" would be offered to the individuals identified through preliminary testing. Although the major ethnic groups in Peterborough are Urdu, Punjabi, Italian, Gujarati, and Chinese, only three minority languages were ultimately selected for training: Gujarati, Urdu, and Italian. This decision was based on prospective student interest among speakers of these languages. At the completion of the language strengthening course, participants were provided 
with intensive interpreter training for ten days as a block (weekends were not included). All in all, the Peterborough project was considered to be a success; much was learned and future projects reflected the results of the organizers' and trainers' experiences (Longley 1984).

In 1986, another community interpreter training course (also affiliated with the Institute of Linguists and the Nuffield Foundation) was offered in Cambridge. Fletcher (1989), whose language combination is Mandarin Chinese/English, describes his experience as a participant in the course developed specifically to train legal interpreters. Initially, the classes included language enhancement components (like the Peterborough project) as well as lectures on the British legal system by local experts and relevant agency representatives. After six months of evening classes which concentrated solely on language enhancement and the workings of the legal system, a two-week intensive course on the techniques of interpretation was offered. The Polytechnic of Central London provided the instructors, who were conference interpreter trainers.

Another development in the United Kingdom worthy of mention is the Polytechnic of Central London's continuing involvement in community interpreter training. In 1989, a postgraduate course for the "training of trainers" of community interpreters was launched. To sum up, Fletcher (1989) writes: "This whole project (meaning the Community Interpreting Project) is undoubtedly the most significant development in community interpreting in the UK" (131).

The London Interpreting Project (LIP) contracts with various government agencies and community groups to offer a variety of courses. Although not strictly interpretation, worthy of mention is LIP's current involvement with the Bilingual Health Advocacy Course which is offered through a cooperative effort with a Family Health Services Authority and St. Bartholomew's Hospital. A 36-week course, it provides inservice training to participants one afternoon per week. Students have their choice of a "skills" option or a "theory" option (Sanders 1992).

\section{Continuing Issues in Community Interpretation}

Although much progress has been made (as illustrated by the projects discussed herein), many problems still remain to be solved and recurring issues must be addressed. First of all, the overwhelming demand for competent interpreters in numerous and varied settings will probably never abate. With a shortage of qualified interpreter educators, more emphasis must be placed on "training of trainer" programs. Second, one 
must accept the fact that many candidates for community interpreter training will require some sort of language enhancement, whether it be in English, in their native language(s), or both. Provisions must be made for this additional component. Third, training must stress the development of a specialized knowledge and procedural base in the particular areas which are targeted. Fourth, it is critical to include ethics and professional responsibility as subjects which go hand-in-hand with the actual skills training. The author is often shocked not only by the kinds of questions she is asked regarding the interpreter's role but also by the anecdotes which are brought to her attention. Fifth, trainees must become attuned to cultural differences and the role they play in both the source and target groups. Sensitivity in this area is mandatory. Sixth, more effort must be made to educate the general public on how to work most efficiently with interpreters. In this connection, interpreters must take it upon themselves to embody professionalism so that service providers may learn and, as a result, contribute to an optimal interpretation experience for everyone involved.

\section{Conclusion}

According to recent statistics, "[b]y the end of the century, 30 per cent of the population under age 35 in European cities will not be living in their country of origin" (Sheppard 1992:33). Whereas the overall population in the United States is projected to grow by about $11 \%$ by the year 2000 , the Hispanic population of the United States is expected to increase by $39.4 \%$ during the same period (Schweda Nicholson 1991). As a result, one can project that the demand for community interpretation services will continue to increase and, most probably, surpass current requirements. In this connection, awareness of changing demographic patterns will be critical in order to stay abreast of permanent changes as well as temporary fluctuations in population distribution.

The current article has described a number of community interpreter training initiatives, highlighting selected developments in the United States and the United Kingdom. To conclude, effective and responsive community interpreter training will require close cooperation among many individuals, governments, and organizations. It is only through a concerted effort on all levels that the field will continue to expand and come closer to attaining its ultimate goal: the provision of professional interpretation services in our complex world, a world in which disparate languages and cultures are increasingly intertwined. 


\section{References}

AUSIT (1992): Invisible interpreters and transparent translators. (A policy statement by the Australian Institute of Interpreters and Translators). Victoria: AUSIT.

Bowen, David and Margareta (Eds.) (1990): American Translators Association Series Volume IV: Interpreting: Yesterday, Today and Tomorrow. Binghamton, NY: Center for Research in Translation, State University of New York.

Burley, Patrizia (1990): Community interpreting in Australia. In: Bowen, 146-153.

Chapman, Ronald (1990): How American courts view defendants' rights to interpreters. In: Bowen, 81-90.

Court Interpreters Act of 1978: (Public Law 95-539). Title 28, Sections 1827 and 1828, page 539.

de Jongh, Elena (1990): The challenge for the court interpreter in Southern Florida. In: Bowen, 91-95.

Downing, Bruce and Tillery, Kate Helms (1992): Professional Training for Community Interpreters. Minneapolis, MN: Center for Urban and Regional Affairs.

Fletcher, Roger (1989): Community interpreting in the UK. Proceedings of the 1989 American Translators Association Conference. Deanna L. Hammond, Editor. 129-132. Medford, NJ: Learned Information, Inc.

Flynn, John (1985): Accreditation of interpreters in Australia. In: Journal of Interpretation 2, 22-26.

Khoon, Wong Fook (1990): Court interpreting in a multiracial society - the Malaysian experience. In: Bowen, 108-116.

Longley, Patricia (1984): What is a community interpreter?. In: The Incorporated Linguist 23, 178-181.

Mindess, Anna (1992): Cross cultural sensitivity: More than a 9 to 5 job. In: Journal of Interpretation 5, 91-94.

Moerman, Ellen (1991): Training court interpreters in the Netherlands. ITI Conference 5 Proceedings. Catriona Picken, Editor. 38-45. London: Aslib (The Association for Information Management).

Molyneux-Berry, Aziza (1992): Interpreting for public services. Paper delivered at the Institute of Translation and Interpreting Conference 6 (1991), Stratford-on-Avon, England.

Morris, Ruth (1990): Interpretation at the Demjanjuk trial. In: Bowen, 101-107.

O'Brien, Lisa (1985): Interpreting in substance abuse treatment settings. In: Journal of Interpretation 2, 99-104.

Per-Lee, Myra, Cogswell, Virginia, and Pace, Carol (1985): Victim/witness: Implications for the interpreter. Journal of Interpretation 2, 105-112.

Roberts, Roda, and Tayler, Marilyn (1990): Development of legal interpreter education in New Jersey. In: Bowen, 70-80.

Robson, Stuart (1993) (November 15): Personal communication. 
Robson, Stuart (1988) (May 10): Personal communication.

Sanders, Marsha (1992): Training for community interpreters. ITI Conference 6 Proceedings. Catriona Picken, Editor. 45-50. London: Aslib (The Association for Information Management).

Schweda Nicholson, Nancy (1994): Forthcoming. Professional ethics for court and community interpreters. American Translators Association Series - Volume VII: Professional Issues in Translation and Interpretation.

Schweda Nicholson, Nancy (1994): In: Press. Training for refugee mental health interpreters. Teaching Translation and Interpreting: Insights, Aims, Visions.

Schweda Nicholson, Nancy (1993): Language planning in the Executive Office for Immigration Review (EOIR). Paper delivered at the Annual Conference of the American Association for Applied Linguistics, Atlanta, Georgia.

Schweda Nicholson, Nancy (1992): Interpretation services for lesser-used languages in the United States Courts: A language planning perspective. Language Problems and Language Planning 16/1, 38-52.

Schweda Nicholson, Nancy (1991): Policy-making for Spanish court interpretation services. Sociolinguistics of the Spanish-Speaking World. Carol A. Klee, Editor. 329-348. Tempe, Arizona: Bilingual Press.

Schweda Nicholson, Nancy (1990a): Linguistic perspectives on courtroom language and interpretation services. Proceedings of the Northeast Conference on Legal Interpretation and Translation. Angela Aguirre, Editor. 65-74. Jersey City, NJ: The Consortium of Educators in Legal Interpretation and Translation at Jersey State College.

Schweda Nicholson, Nancy (1990b): Consecutive note-taking for community interpretation. In: Bowen, 136-145.

Schweda Nicholson, Nancy (1989): Ad hoc court interpreters in the United States: Equality, inequality, quality? In: Meta 34/4: 711-723.

Schweda Nicholson, Nancy (1987): Beyond the Court Interpreters Act of 1978: The Federal Court Interpreters Advisory Board. Proceedings of the 1987 American Translators Association Conference. Karl Kummer, Editor. 281-286. Medford, NJ: Learned Information, Inc.

Schweda Nicholson, Nancy (1986a): Court interpreter training: A growing need. Proceedings of the 1985 Eastern Michigan University Conference on Languages for Business and the Professions. Geoffrey M. Voght, Editor. (U.S. Department of Education). ERIC Clearinghouse for Languages and Linguistics, Microfiche Collection. 53 pages.

Schweda Nicholson, Nancy (1986b): Language planning and policy development for court interpretation services in the United States. In: Language Problems and Language Planning 10/2, 140-157.

Shackman, Jane (1984): The Right to Be Understood: A Handbook on Working With, Employing and Training Community Interpreters. Cambridge: National Extension College.

Sheppard, Colin (1992): Language and the law. In: Police Review (January 3), 33. 
Toso, Julie (1988): Language planning for community interpreting services. Unpublished manuscript.

Wilder, Patricia (1985): Assessing the present and projected supply and demand situation with interpreter services in Minnesota. In: Journal of Interpretation 2, 58-82. 
